\title{
Article \\ Study of DC Magnetron Sputtered Nb Films
}

\author{
He Gao, Shijian Wang, Da Xu, Xueshen Wang $\mathbb{D}^{\mathbb{D}}$, Qing Zhong, Yuan Zhong, Jinjin Li and Wenhui Cao * \\ National Institute of Metrology, Beijing 100029, China; gaohe@nim.ac.cn (H.G.); wangshj@nim.ac.cn (S.W.); \\ xuda@nim.ac.cn (D.X.); wangxs@nim.ac.cn (X.W.); zhongq@nim.ac.cn (Q.Z.); zhongyuan@nim.ac.cn (Y.Z.); \\ jinjinli@nim.ac.cn (J.L.) \\ * Correspondence: caowh@nim.ac.cn; Tel.: +86-010-64526134
}

check for updates

Citation: Gao, H.; Wang, S.; Xu, D.; Wang, X.; Zhong, Q.; Zhong, Y.; Li, J.; Cao, W. Study of DC Magnetron Sputtered Nb Films. Crystals 2022, 12, 31. https://doi.org/10.3390/ cryst12010031

Academic Editors: John A. Mydosh and Alberto Girlando

Received: 15 November 2021

Accepted: 14 December 2021

Published: 26 December 2021

Publisher's Note: MDPI stays neutral with regard to jurisdictional claims in published maps and institutional affiliations.

Copyright: (C) 2021 by the authors. Licensee MDPI, Basel, Switzerland. This article is an open access article distributed under the terms and conditions of the Creative Commons Attribution (CC BY) license (https:// creativecommons.org/licenses/by/ $4.0 /)$.

\begin{abstract}
As} \mathrm{Nb}$ films are widely used as superconducting electrodes of Josephson junctions, it is important to investigate the properties of $\mathrm{Nb}$ films in order to fabricate high-quality Josephson junctions. In this work, we conducted a comprehensive analysis of the relationships among the properties of DC magnetron sputtered $\mathrm{Nb}$ films with a constant power fabricated at the National Institute of Metrology (China). The film properties, including superconductivity, stress, lattice constant, and surface roughness, were investigated. It was found that in the case of constant power and Ar pressure, the stress and other parameters of the $\mathrm{Nb}$ films can maintain a relatively stable state during the continuous consumption of the target material.
\end{abstract}

Keywords: superconducting films; DC magnetron sputtering; Ar pressure; stress

\section{Introduction}

DC magnetron sputtering is one of the thin-film deposition manufacturing processes which are applied in high-vacuum chambers filled with argon gas. Ar becomes ionized and bombards the target when exerting a DC voltage to the target material; as a result, the atoms are ejected from the target to be deposited onto the substrate. Since the 1960s, studies have been carried out to determine niobium $(\mathrm{Nb})$ film deposition using $\mathrm{DC}$ magnetron sputtering in order to obtain high-quality superconducting electrodes: changing the impurity gas content in $\mathrm{Nb}$ films by ion bombarding the sample substrate [1] to improve the residual resistance ratio and superconducting transition temperature of $\mathrm{Nb}$ films, changing the distribution of $\mathrm{Nb}$ film stress by Ar ion bombardment [2], etc. Further studies were carried out on the relationships between the $\mathrm{Nb}$ film thickness, the Ar pressure, film stress, and superconducting transition temperature [3,4]; conclusions suggested that the transition temperature is hardly changed with the variation in the film thickness when the $\mathrm{Nb}$ film thickness is more than $200 \mathrm{~nm}$ [5], and low-stress $\mathrm{Nb}$ films can be obtained by different sputtering conditions. There are several methods that can be used to ensure the $\mathrm{Nb}$ film is maintained in a low-stress condition and hardly changes within a $\mathrm{Nb}$ target material's lifespan, such as maintaining a constant cathode voltage [6], maintaining a constant Ar pressure and cathode current [7], and maintaining a constant sputtering power and pressure [8]. It is also believed that the stress mainly depends on the sample load, sample preparation, and the structure of the target $[9,10]$. Many studies have been conducted on the effect of $\mathrm{Nb}$ film stress on Josephson junctions. The stress can be released in the process of etching and may cause damage if it is too high [11,12]. Other studies on the surface roughness of films have shown that low-stress films often express a relatively small value of roughness $[13,14]$. It can be seen that the properties of $\mathrm{Nb}$ films are relevant to many factors, and different deposition conditions should be considered for different instruments.

Currently, DC magnetron sputtering is the most common method to deposit superconducting $\mathrm{Nb}$ films and is usually applied in making superconducting quantum interference detectors [15], ultrafast digital electronics [16], SIS receivers [17], etc. Our purpose of obtaining high-quality $\mathrm{Nb}$ films is for Josephson voltage standards $[18,19]$. 
The main property parameters of $\mathrm{Nb}$ films used for Josephson junctions are stress, superconducting transition temperature, residual resistance ratio, lattice constant, and surface roughness. Typically, a higher quality of $\mathrm{Nb}$ films exhibits a lower compressive stress with a residual resistance ratio of over 3 , a smaller value of roughness, a higher superconducting transition temperature, and a lattice constant close to bulk $\mathrm{Nb}$. This work mainly focused on the $\mathrm{Nb}$ film properties under a constant sputtering power and different Ar pressures, as well as the influence of the target-to-substrate distance.

\section{Deposition and Measurements}

The instrument used for $\mathrm{Nb}$ film deposition was a DC magnetron sputtering system manufactured by Kurt J Lesker company, mainly consisting of a process chamber and a very small load-lock chamber. The cryo-pumped process chamber had a base pressure of about $1 \times 10^{-8}$ Torr and was equipped with several guns. The sputtering target was placed in the bottom of the chamber, while the substrate was placed in the middle of the top level. The substrate that was typically used was a 2-inch Si wafer coated with $175 \mathrm{~nm} \mathrm{SiO}$ and cooled to about $17^{\circ} \mathrm{C}$ by clamping to a water-cooled $\mathrm{Cu}$ substrate holder. The 3-inch $\mathrm{Nb}$ target inclined upward toward the center of the substrate. During sputtering, the substrate was kept at a uniform rotation for the purpose of obtaining a uniform film thickness, as depicted in Figure 1.
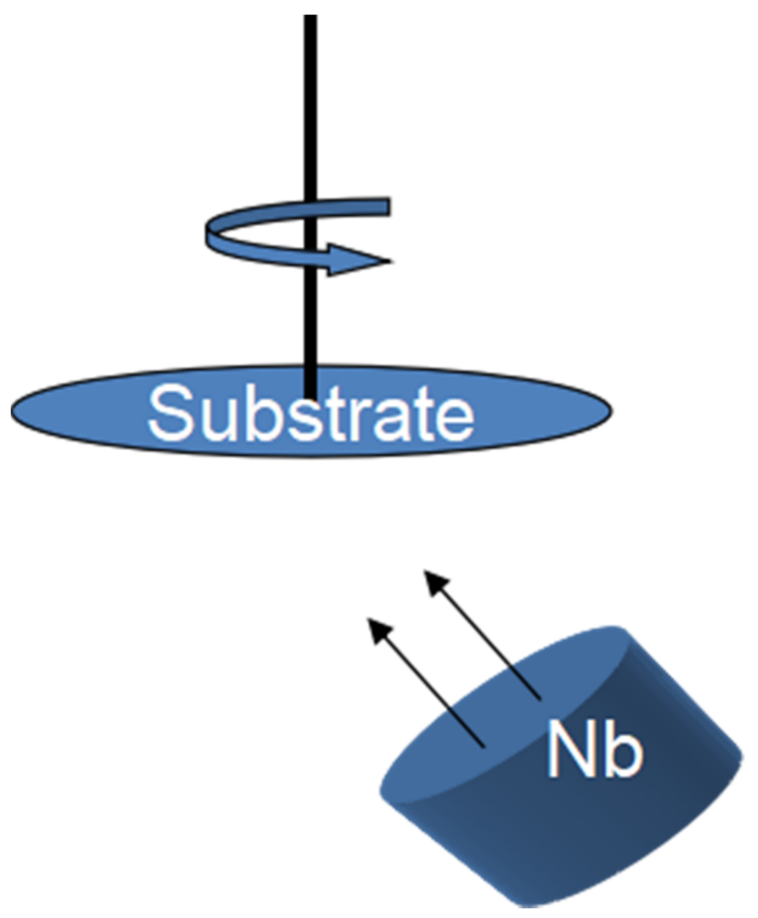

Figure 1. A brief overview of the sample preparation.

Firstly, the target-to-substrate distance was set to $110 \mathrm{~mm}$, and the sputtering target power was fixed at $500 \mathrm{~W}$. Nb films were deposited at different Ar pressures. The deposition rate was typically $0.54 \mathrm{~nm} / \mathrm{s}$ at $4 \mathrm{mTorr}$, with an Ar flow of about $20 \mathrm{Sccm}$, and the inhomogeneity of the film thickness over the substrate was less than $5 \%$. The parameters of $\mathrm{Nb}$ films were then measured and analyzed.

\subsection{Superconducting Transition Temperature}

A curve of the $\mathrm{Nb}$ film resistance under the change in temperature from 300 to $4.2 \mathrm{~K}$ was depicted in a cryogenic measurement system based on a liquid helium dewar. The superconducting material changed from a resistive state to a superconducting state within a narrow transition width. Usually, the temperature for which the resistance equals half of 
its normal value is called the superconducting transition temperature $T_{\mathrm{c}}$. For bulk $\mathrm{Nb}$, the $T_{\mathrm{c}}$ was $9.2 \mathrm{~K}$. The measured $T_{\mathrm{c}}$ of $\mathrm{Nb}$ films deposited at different Ar pressures is displayed in Figure 2.

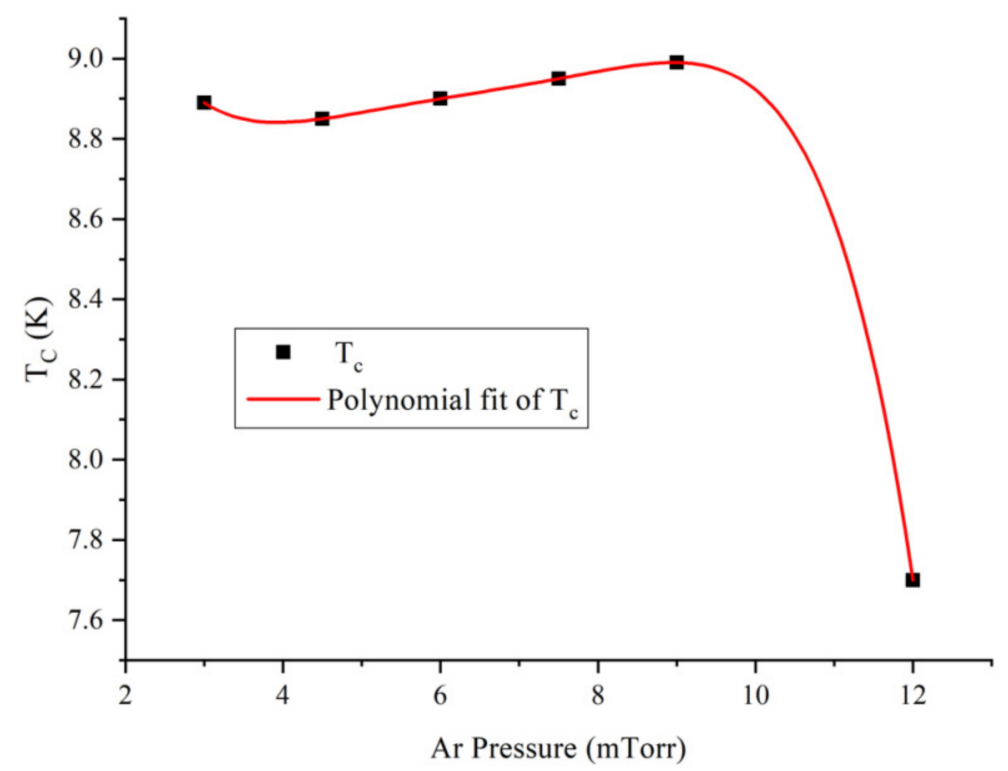

Figure 2. The superconducting transition temperature of $\mathrm{Nb}$ films versus Ar pressure.

The $T_{\mathrm{c}}$ was around $8.9 \mathrm{~K}$ and did not change obviously as the pressure was increased when it was previously relatively low; however, it dropped quickly as the pressure rose above 9 mTorr. Two factors may have contributed to this drop: one is the impurity of $\mathrm{Ar}$, and the other is the decreased deposition rate. Both of them may become worse as the pressure rises to some extent and therefore may result in film pollution.

\subsection{Residual Resistance Ratio}

The residual resistance ratio $(R R R)$ of $\mathrm{Nb}$ films is usually defined as the ratio of the resistance at $300 \mathrm{~K}$ to the resistance at $10 \mathrm{~K}$. A higher value of $R R R$ reflects a higher quality of $\mathrm{Nb}$ films. Figure 3 depicts the relationship between the measured $R R R$ and Ar pressure; as can be seen, the $R R R$ decreased as the pressure increased.

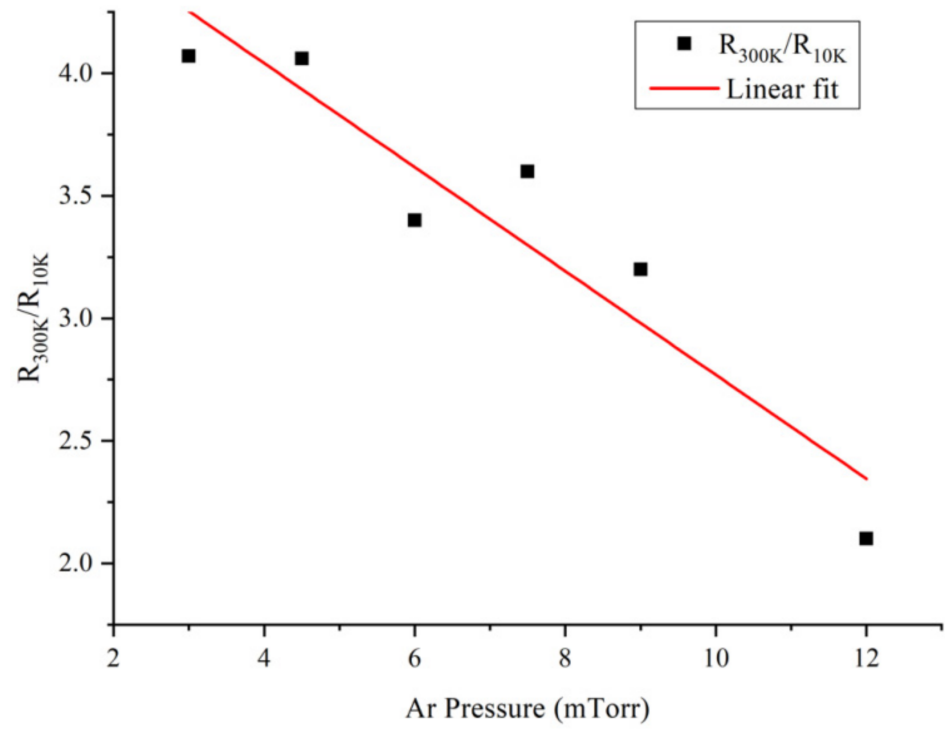

Figure 3. The residual resistance ratio of $\mathrm{Nb}$ films versus Ar pressure. 


\subsection{Film Stress}

Film stress can be calculated according to Young's modulus of the substrate material and the changes in the substrate curvature before and after coating a layer of the film. The stress of $\mathrm{Nb}$ films deposited at different pressures was measured in a laser measurement system, as depicted in Figure 4.

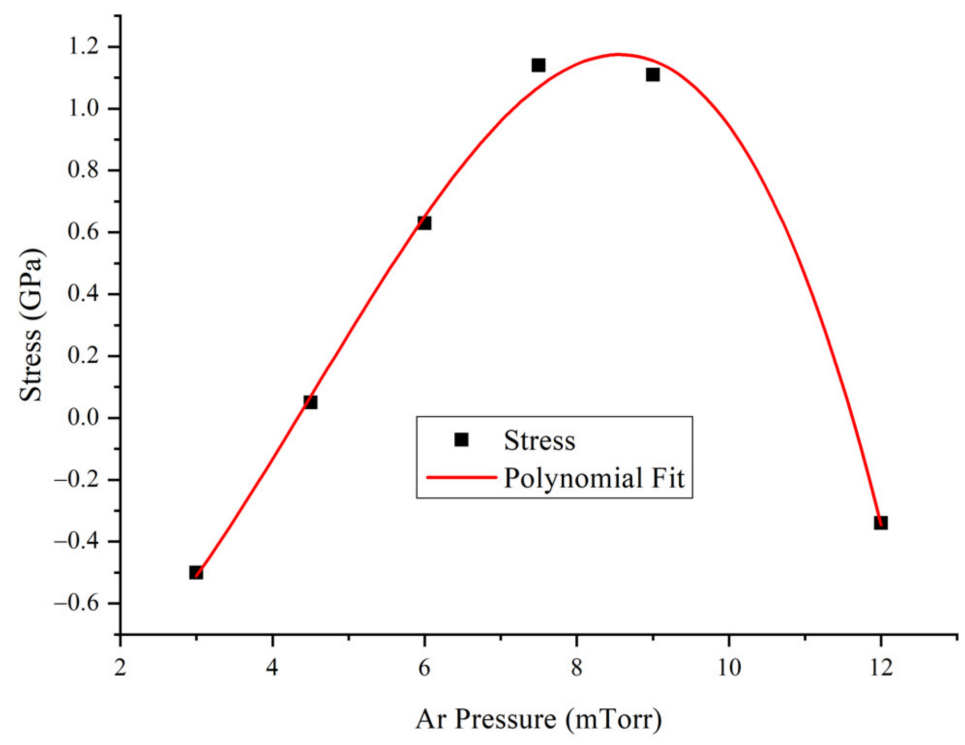

Figure 4. The stress of $\mathrm{Nb}$ films versus Ar pressure.

The film stress was relatively highly compressive at a relatively low Ar pressure, gradually moved to tensile as the pressure increased above $4.5 \mathrm{mTorr}$, reached the maximum value of about $1.1 \mathrm{GPa}$ at around 9 mTorr, and then moved back to compressive above 9 mTorr. It was also found that this relationship between stress and Ar pressure was stable and repeatable as long as the sputtering power was fixed at $500 \mathrm{~W}$ and target-tosubstrate distance was $110 \mathrm{~mm}$; thus, the $\mathrm{Nb}$ film stress can be controlled by adjusting the Ar pressure.

\subsection{Lattice Constant}

The lattice constant of $\mathrm{Nb}$ films was measured by an X-ray diffractometer, the results of which are depicted in Figure 5. The trend of lattice constant changes with Ar pressure exhibited high similarity to the trend of film stress changes with pressure in Figure 4 . The lattice constant of $\mathrm{Nb}$ films at 3 mTorr was larger than that of bulk $\mathrm{Nb}$ (nearly $0.33 \mathrm{~nm}$ ), and its stress was quite compressive. As the pressure increased to about $4.5 \mathrm{mTorr}$, the lattice constant decreased to $0.33 \mathrm{~nm}$, and its stress moved close to zero. Above $4.5 \mathrm{mTorr}$, the lattice constant reached the minimum value near 9 mTorr and then started to rise to a high value. The stress also reached a maximum value and started to drop at around 9 mTorr.

\subsection{Surface Roughness}

The surface roughness of $\mathrm{Nb}$ films was measured with an atomic force microscope. As depicted in Figure 6, the surface roughness was the lowest at the lowest Ar pressure, reached the maximum value at 9 mTorr, and then fell again. This relationship between roughness and Ar pressure was also highly similar to that of stress or the lattice constant, the only difference being that the roughness did not fall to the initial level at the highest pressure. 


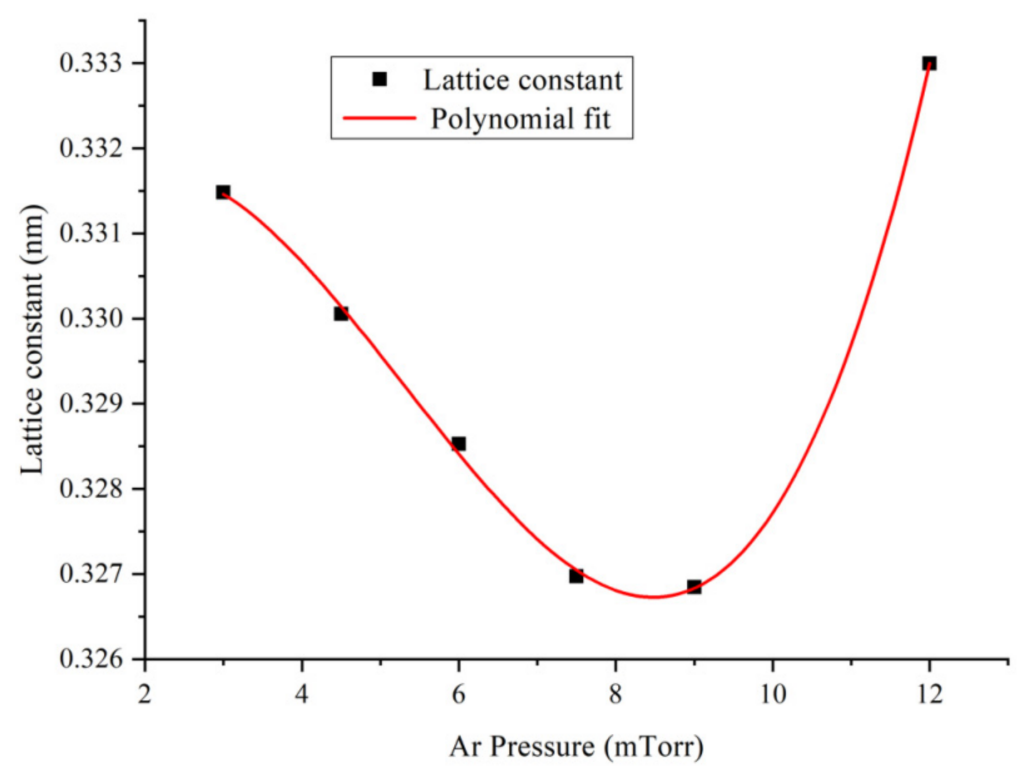

Figure 5. The lattice constant versus Ar pressure.

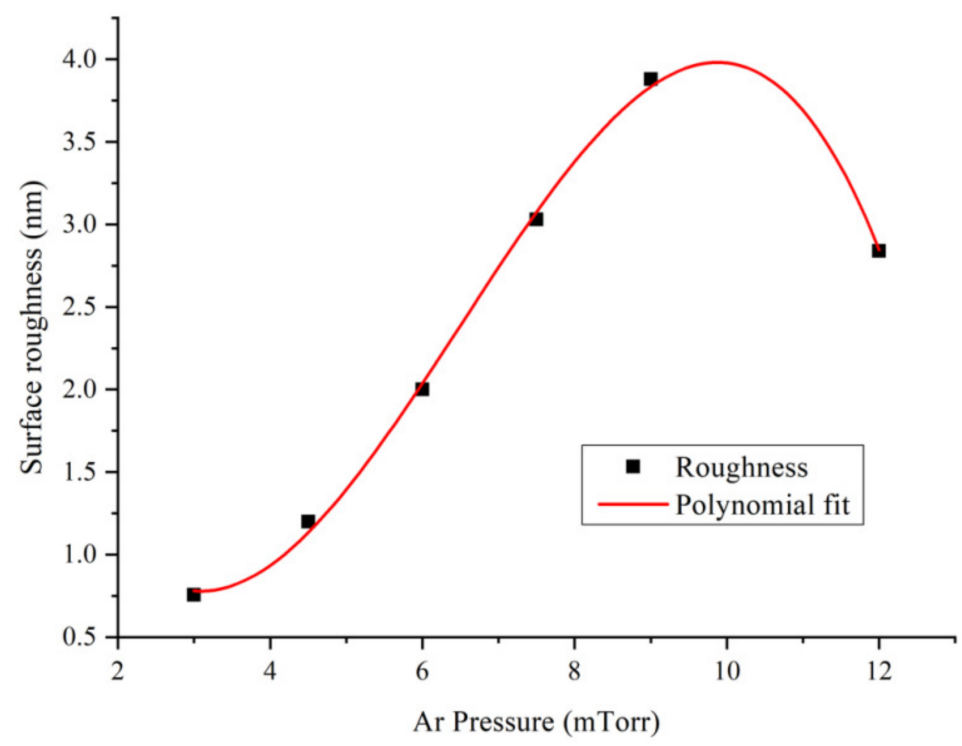

Figure 6. The surface roughness versus Ar pressure.

\section{Discussion and Supplements}

For application as superconducting electrodes of Josephson junctions, a high value of the $R R R$, a smooth surface, and slightly compressive stress are required for $\mathrm{Nb}$ films. Based on all the results above, a stress-free $\mathrm{Nb}$ film can be acquired at around 4.5 mTorr when the sputtering power is $500 \mathrm{~W}$ and the target-to-substrate distance is $110 \mathrm{~mm}$. The values of the $T_{\mathrm{c}}, R R R$, lattice constant, and roughness of this stress-free $\mathrm{Nb}$ film were all in a suitable range, that is, a $T_{\mathrm{c}}$ of up to $9 \mathrm{~K}$, an $R R R$ of over 4 , a lattice constant near $0.33 \mathrm{~nm}$, and a roughness between 1 and $2 \mathrm{~nm}$. The pressure of $4.2 \mathrm{mTorr}$ can be considered as a suitable Ar pressure for slightly compressive stress, which causes $\mathrm{Nb}$ films to be more compact. To summarize, the Ar pressure is the most important factor in DC magnetron sputtering for the equipment; $\mathrm{Nb}$ films at the Ar pressure point causing slightly compressive stress exhibit other excellent properties.

The trend of $\mathrm{Nb}$ film stress changes with pressure was roughly consistent with the viewpoints of C.T. Wu [4] and K. Kurodal [11]. The curve shapes are very similar even though slight differences are present: the stress-free Ar pressure was about 1.4 $\mathrm{Pa}$ in [4] and 1.06 Pa in [11], and the stress dropped more gently after reaching the maximum tensile 
value in $[4,11]$. This slight difference may be due to the differences in the target-to-substrate distance, chamber structure, and sputtering target model.

The influence of the target-to-substrate distance on film properties was also worth further investigation; without any other change, new batches of $\mathrm{Nb}$ films were produced, and the properties were analyzed just as above after the target-to-substrate distance was increased to $130 \mathrm{~mm}$. Figure 7 shows the film stress and $T_{\mathrm{c}}$ of the new batches at different $\mathrm{Ar}$ pressures. The trend is similar to that in Figure 2; Figure 4, and there is no obvious change; only the pressure moves left to a lower position. The pressure point of the maximum value of $T_{\mathrm{c}}$ or stress shifts from 9 to $7.5 \mathrm{mTorr}$.

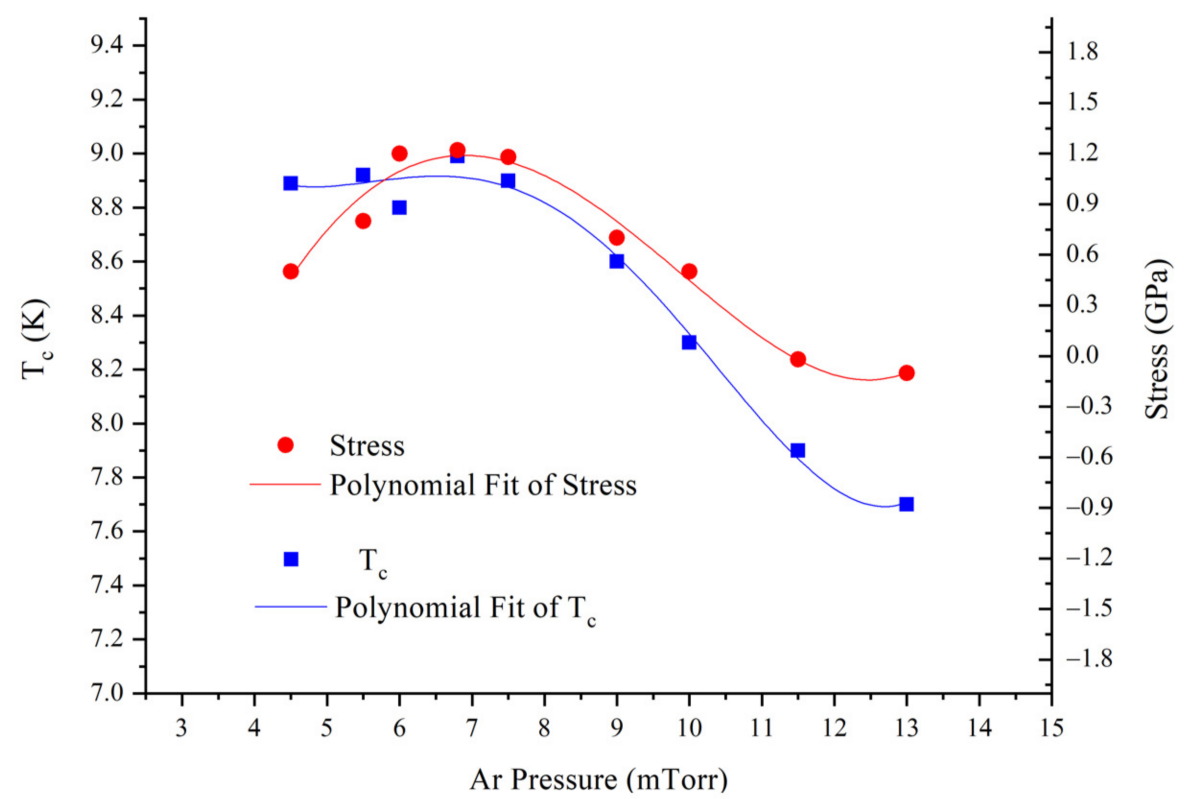

Figure 7. Film stress and Tc versus Ar pressure after the target-to-substrate distance changes to $130 \mathrm{~mm}$.

This leftward shift may be explained by the film formation mechanism. This could often happen because Ar ions change to Ar atoms shortly after sputtering the target material. The anti-sputtering ions are energetic, and the effect of bombardment can affect the properties of $\mathrm{Nb}$ films [14]. The distance from the splashed-out Ar atoms to substrate becomes larger when the target-to-substrate distance increases, and thus the probability of Ar atoms bombarding other atoms increases. As a result, the bombardment energy onto the films from Ar atoms decreases if the pressure is kept constant. Meanwhile, if the pressure decreases, the mean free path of Ar atoms is increased again, resulting in a lower probability of bombarding other atoms, and therefore the bombardment energy onto films increases. Therefore, the film properties could return to a state that is similar to the initial one before increasing the target-to-substrate distance and decreasing the Ar pressure.

Among the past few years' experiments on this sputtering equipment, the targetto-substrate distance was always kept about $90 \mathrm{~mm}$, and the optimal Ar pressure was increased based on the analysis above. Slightly compressive stress films are acquired at about 5 mTorr. The sputtering power is always set at $500 \mathrm{~W}$ throughout the lifespan of a $\mathrm{Nb}$ target, that is, from a brand-new target to the condition of $90 \%$ consumption. By fine-tuning of less than 0.2 mTorr around 5 mTorr, the film stress can be maintained as slightly compressive. For our sputtering equipment, as long as the power and Ar pressure remain unchanged, the film stress can stay in a relatively stable state, which is consistent with the experimental result of N.N. Iosad in [8].

All the samples discussed above were not RF cleaned before coating. Film stress with an RF clean could lead to a different film stress [10], and thus it is worthy of future study. Film stress with and without an RF clean was also measured under the same conditions; 
the result suggests that $\mathrm{Nb}$ film stress increases about $100 \mathrm{MPa}$ with a $100 \mathrm{~W}$ RF clean for 2 min compared to without an RF clean. The assumed reason for this result is that some gases absorbed on the surface of the substrate were not completely released in a short time in the vacuum chamber, which may influence the film formation process. Most absorbed gas molecules can be removed by Ar ionic bombardment in an RF clean for a short time. It was also found that similar effects to an RF clean can be achieved by cleaning with acetone, isopropanol, and deionized water and baking for several minutes; this is roughly consistent with the experimental result of R.B. Bass [10]. A type of clean similar to an RF clean or ion milling is strongly recommended during substrate preparation in order to clean the absorbed contamination and obtain films with uniform stress; the method we usually utilize is solvent cleaning.

\section{Conclusions}

The properties of $\mathrm{DC}$ magnetron sputtered $\mathrm{Nb}$ films with a constant power and different Ar pressures were investigated, as well as the influence of changing the targetto-substrate distance. It was found that in the case of constant power, there is a strong relationship between film stress and other parameters, and all the property parameters can be maintained in a suitable and relatively stable range at a constant pressure during the lifespan of the target material. The rules and methods for high-quality $\mathrm{Nb}$ film deposition can be determined based on this study.

Author Contributions: Conceptualization, W.C.; methodology, W.C.; software, W.C.; validation, S.W., X.W., Q.Z., Y.Z. and J.L.; formal analysis, W.C.; investigation, H.G., S.W., D.X., Y.Z. and W.C.; resources, W.C. and J.L.; data curation, H.G., S.W., W.C.; writing—original draft preparation, H.G.; writingreview and editing, W.C. and H.G.; visualization, S.W.; supervision, W.C.; project administration, J.L.; funding acquisition, Y.Z. All authors have read and agreed to the published version of the manuscript.

Funding: This research was supported in part by the National Key Research and Development Program of China under Grant 2018YFB2003401, in part by the National Natural Science Foundation of China under Grant 61971471, and in part by the Strategic Priority Research Program of Chinese Academy of Sciences under Grant XDC07010100.

Institutional Review Board Statement: Not applicable.

Informed Consent Statement: Not applicable.

Data Availability Statement: Data is contained within the article.

Conflicts of Interest: The authors declare no conflict of interest.

\section{References}

1. Frerichs, R.; Kircher, C.J. Properties of Superconducting Niobium Films Made by Asymmetric ac Sputtering. J. Appl. Phys. 1963, 34, 3541-3543. [CrossRef]

2. Cuomo, J.J.; Harper, J.; Guarnieri, C.R.; Yee, D.S.; Harmmond, R.H. Modification of Niobium film Stress by low-energy Ion Bombardment During Deposition. J. Vac. Sci. Technol. 1982, 20, 349-354. [CrossRef]

3. Hoffman, D.W.; Thornton, J.A. The Compressive Stress Transition in Al, V, Zr, Nb, and W metal Films Sputtered at Low Working Pressures. Thin Solid Films 1977, 45, 387-396. [CrossRef]

4. Wu, C.T. Intrinsic Stress of Magnetron-Sputtered Niobium Films. Thin Solid Films 1979, 64, 103-110. [CrossRef]

5. Wolf, S.A.; Kennedy, J.J.; Nisenoff, M. Properties of Superconducting rf Sputtered Ultrathin Films of Nb. J. Vac. Sci. Technol. 1976, 13, 145-147. [CrossRef]

6. Imamura, T.; Shiota, T.; Hasuo, S. Fabrication of High Quality Nb/A1Ox-Al/Nb Josephson Juctions: I- Sputtered Nb Films for Junction Electrodes. IEEE Trans. Appl. Supercond. 1992, 2, 1-14. [CrossRef]

7. Amos, R.S.; Breyer, P.E.; Huang, H.H.; Lichtenberger, A.W. Stress and Source conditions of dc Magnetron Sputtered Nb Films. IEEE Trans. Appl. Supercond. 1995, 5, 2326-2329. [CrossRef]

8. Iosad, N.N.; Klapwijk, T.M.; Polyakov, S.N.; Roddatis, V.V.; Kov'ev, E.K.; Dmitriev, P.N. Properties of DC Magnetron Sputtered $\mathrm{Nb}$ and $\mathrm{NbN}$ Films for Different Source Conditions. IEEE Trans. Appl. Supercond. 1999, 9, 1720-1723. [CrossRef]

9. Clark, W.W.; Beatrice, J.M.; Lichtenberger, A.W. Effects of Geometry and Hardware on the Stress of Nb Thin Films. IEEE Trans. Appl. Supercond. 2001, 11, 3824-3827. [CrossRef] 
10. Bass, R.B.; Lichtenberger, L.T.; Lichtenberger, A.W. Effects of Substrate Preparation on the Stress of Nb Thin Films. IEEE Trans. Appl. Supercond. 2003, 13, 3298-3300. [CrossRef]

11. Kuroda, K.; Yuda, M. Niobium-stress influence on Nb/Al-oxide/Nb Josephson Junctions. J. Appl. Phys. 1988, 63, 2352-2357. [CrossRef]

12. Imamura, T.; Hasuo, S. Effects of intrinsic stress on submicrometer Nb/AIOx/Nb junctions. IEEE Trans. Magn. 1989, 25, 1119-1122. [CrossRef]

13. Tsukada, K.; Kawai, J.; Uehara, G.; Kado, H. Relationship of Nb Suface Morphology and Al Coverage to the Intrinsic Stress of Magnetron-Sputtered Nb Films. IEEE Trans. Appl. Supercond. 1993, 3, 2944-2946. [CrossRef]

14. Liu, J.; Li, J.; Li, T.; Li, T.; Wu, W.; Chen, W. Study of Stress and Morphology of Superconducting Niobium Thin Films. IEEE Trans. Appl. Supercond. 2009, 19, 245-248.

15. Clarke, J.; Goubau, W.M.; Ketchen, M.B. Tunnel junction dc SQUID: Fabrication, operation, and performance. J. Low Temp. Phys. 1976, 25, 99-144. [CrossRef]

16. Tolpygo, S.K.; Bolkhovsky, V.; Weir, T.J.; Wynn, A.; Gouker, M.A. Advanced Fabrication Processes for Superconducting Very Large Scale Integrated Circuits. IEEE Trans. Appl. Supercond. 2016, 26, 1-10. [CrossRef]

17. Zacher, R.A.; Saulnier, G.; Fritz, G.G.; Vechten, D.; Kang, J. Nb/Al/AlOx/Nb superconducting tunnel junctions as x-ray detectors. J. Low Temp. Phys. 1993, 93, 581-586. [CrossRef]

18. Dresselhaus, P.D.; Elsbury, M.M.; Olaya, D.; Burroughs, C.J.; Benz, S.P. 10 Volt Programmable Josephson Voltage Standard Circuits Using NbSi-Barrier Junctions. IEEE Trans. Appl. Supercond. 2011, 21, 693-696. [CrossRef]

19. Cao, W.; Li, J.; Wang, L.; Zhong, Y.; Zhong, Q. Quadruple-stacked Nb/NbxSi1-x/Nb Josephson junctions for large-scale array application. Chin. Phys. B 2020, 29, 067404. [CrossRef] 